\title{
Quality of life for patients with major depression in Taiwan: A model-based study of predictive factors
}

\author{
Lyinn Chung ${ }^{\mathrm{a}}$, Ay-Woan Pan ${ }^{\mathrm{b}, \mathrm{c}}$, Ping-Chuan Hsiung ${ }^{\mathrm{d}, *}$ \\ ${ }^{a}$ Department of Statistics, National Taipei University, Taipei, Taiwan \\ ${ }^{\mathrm{b}}$ Department of Occupational Therapy, National Taiwan University, Taipei, Taiwan \\ ${ }^{\mathrm{c}}$ Department of Psychiatry, National Taiwan University Hospital, Taipei, Taiwan \\ ${ }^{\mathrm{d}}$ Department of Social Work, National Taiwan University, Taipei, Taiwan
}

Received 10 October 2007; received in revised form 21 March 2008; accepted 5 April 2008

\begin{abstract}
The 'quality of life' (QOL) for patients suffering from depression is affected by four factors: stigma, social support, mastery and depressive symptoms. The purpose of this study was to develop and empirically validate an appropriate path model for the QOL of patients suffering from major depression. We recruited a total of 237 patients suffering from depression from the outpatient psychiatry department of a university-affiliated hospital in northern Taiwan. The sample was predominantly female (74.3\%), had at least a high school level of education (79.7\%), had a mean age of 46.95 years, and were living with their families (87.3\%). Path analysis was used to identify the 'best fit' model for the QOL of the patients in four domains: physical, psychological, social and environmental. The key determinant for all QOL domains is found to be the intensity of the depressive symptoms, with social support also affecting QOL both directly and indirectly, whilst stigma is found to have an indirect effect on QOL mediated by the intensity of the depressive symptoms, mastery and social support. We conclude that more effective improvements in all aspects of QOL for patients suffering from depression could be achieved by the provision of comprehensive intervention programs aimed at reducing stigma, as well as placing greater emphasis on a reduction in the patients' depressive symptoms, and enhancements to their social support and mastery.
\end{abstract}

(C) 2008 Elsevier Ireland Ltd. All rights reserved.

Keywords: Stigma; Social support; Mastery; Depressive symptoms; Path analysis

\section{Introduction}

Depression is projected to become the second leading cause of global disability by 2020 (World Health

\footnotetext{
* Corresponding author. Department of Social Work, National Taiwan University, No. 1, Sec. 4 Roosevelt Rd, Taipei 10617, Taiwan ROC. Tel.: +1188622367 3248; fax: +11886223673248.

E-mail address: pchsiung@ntu.edu.tw (P.-C. Hsiung).
}

Organization, 2004). Patients suffering from major depression are reported to have poorer quality of life (QOL) than both the general population and otherwise healthy persons with chronic diseases (Bonicatto et al., 2001; Angermeyer et al., 2002; Michalak et al., 2004). A correlation has been noted between the QOL for patients suffering from depression and socio-demographic factors, including age and gender (Carpiniello et al., 1997; Rüesch et al., 2004; Trompenaars et al., 2005; Pan et al., 2006), the intensity of depressive symptoms 
(Carpiniello et al., 1997; Berlim et al., 2005; Munoz et al., 2005; Trompenaars et al., 2005; Pan et al., 2006) and social support (Trompenaars et al., 2005).

An additional factor adversely affecting the QOL of patients suffering from mental illness is perceived stigma (Rosenfield, 1992, 1997; Link et al., 2001; Corrigan et al., 2003); nevertheless, in patients with chronic mental illness, the negative effects of such perceived stigma can be mitigated by the adoption of psychiatric services which promote a sense of 'mastery' (Rosenfield, 1992, 1997). However, the study of the impact of perceived stigma on patients with mood disorders is a rather recent development, with such studies finding that higher perceived stigma has a significant association with the severity of the depression (Pyne et al., 2004), predicted impaired social functioning (Perlick et al., 2001) and predicted discontinuation of treatment (Sirey et al., 2001).

The causal relationships between the demographic factors (age, gender), intensity of the depressive symptoms, perceived stigma, social support, sense of mastery and QOL have yet to be tested in patients suffering from major depression. This study therefore sets out to delineate the relationships between QOL and these six predictive variables by reviewing the relevant literature, proposing a hypothetical path $\operatorname{model}^{1}$, and empirically validating this model in a sample of patients suffering from major depression. A validated model is necessary if we are to facilitate an understanding of the interrelationships between these variables and to guide interventions that might improve the QOL of patients suffering from depression.

Actual experience of being discriminated against and the potential for stigmatization continue to be a recurrent theme in patients suffering from mental disorders (Link et al., 1999; Corrigan et al., 2003). One predictive QOL variable, 'stigma', has been found to be related to depressive-anxiety type symptoms, and has also been shown to have a negative effect on life satisfaction, which is partly mediated by self-concept, including 'mastery' (Markowitz, 1998). In other chronic illnesses, stigma has been shown to have a direct effect on life satisfaction, as well as an indirect effect, mediated by social support (Heckman,

\footnotetext{
${ }^{1}$ The merits of path analysis are its ability to interpret linear relationships between a set of variables and to decompose the correlations into direct and indirect effects (Pedhazur, 1982). The path analysis results reveal the exact effects of the predictive variables on QOL and the relative importance of each predictor in the causal model. These effects are represented by standardized path coefficients.
}

2003). According to modified labeling theory, the stigma of mental illness is seen as being problematic because it can damage the sense of self-concept among mental patients (Link et al., 1987; Rosenfield, 1997).

Another predictive QOL variable is 'social support'. People with stronger social support are more likely to receive messages of empathy, encouragement and validation, all of which can enhance their QOL (Wills, 1998). Indeed, social rejection is a persistent source of social distress for patients suffering from mental illness following their discharge from hospital. Such experiences increase the feelings of self-deprecation, which in turn, weaken their sense of mastery (Wright et al., 2000).

'Mastery', a further predictive QOL variable, is seen as a personal resource which can moderate, or at least help a person to cope with, the effects of stress (Rosenfield, 1992). A low sense of mastery affects QOL because it leads to feelings of hopelessness and passivity (Veblen, 1899; Merton, 1946; Rotter, 1966; Pearlin et al., 1981; Rosenfield, 1986), with such diminished mastery leaving a person vulnerable to experiences of depressive symptoms (Pearlin et al., 1981). Thus, it is suggested that the primary task in psychotherapy for the chronic mentally ill is to raise their overall sense of mastery (Lamb, 1976, 1982; Bachrach, 1987). In Asian society, males tend to have a stronger sense of mastery than females (Chung et al., 2003), whilst older people have reportedly lower levels of mastery than younger people (Ben-Zur, 2002).

Our hypotheses are presented as follows:

Hypothesis 1. More advanced age will be associated with a lower level of mastery and lower QOL in the four domains.

Hypothesis 2. As compared with the male group, the female group will tend to have a lower level of mastery and lower QOL.

Hypothesis 3. A lower level of depressive symptoms will be correlated with higher QOL.

Hypothesis 4. A higher level of stigma will be associated with a higher level of depressive symptoms, lower QOL, and a lower level of mastery and social support.

Hypothesis 5. A higher level of social support will be associated with a lower level of depressive symptoms, a higher level of mastery and higher QOL.

Hypothesis 6. A higher level of mastery will be associated with a lower level of depressive symptoms and higher QOL. 


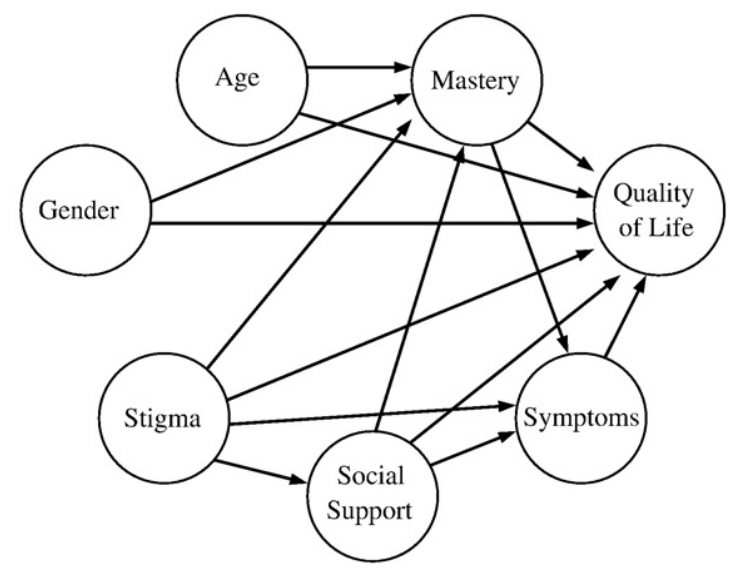

Fig. 1. Initial path model for the four quality of life domains.

Fig. 1 illustrates the proposed comprehensive predictive model for the QOL of patients suffering from major depression.

\section{Methodology}

\subsection{Subjects and setting}

A cross-sectional design was adopted to facilitate the survey of a convenience sample of outpatients suffering from major depression recruited from the psychiatric outpatient clinic of the National Taiwan University Hospital in Taipei. On average, 70,000 people are treated within this clinic each year by a team which includes psychiatrists, psychiatric nurses and social workers. Following approval for this study by the Institutional Review Board of the hospital, the hospital psychiatrists were asked to refer only those outpatients diagnosed with major depression who had no co-morbidity with other mental disorders.

A diagnosis was established by an attending psychiatrist (in accordance with ICD-10 diagnostic criteria) during the patient's first visit to the clinic, based upon an interview which lasted about $40 \mathrm{~min}$. Between March 2004 and April 2005, 263 patients were invited to join the study, of which 237 agreed to participate and provided their signed, informed consent; this yielded a response rate of $90.1 \%$. The symptom severity of these patients, all of whom were actively engaged in treatment, was evaluated by use of the Depression Scale of the Center for Epidemiological Studies.

\subsection{Instruments}

\subsubsection{Scale for intensity of depressive symptoms}

Intensity of the depressive symptoms was measured by the 20-item 'depression scale' of the Center for
Epidemiological Studies (CES-D - Chinese version) (Chien and Cheng, 1985), with the internal consistency reliabilities (Cronbach's alphas) in the prior studies ranging between 0.87 and 0.90 (Yu, 2004). Responses to items were scored from 0 (never, or rarely) to 3 (mostly, or all of the time), with total scores ranging from 0 to 60 . The internal consistency reliability (Cronbach's alpha) in this study was 0.95 .

\subsubsection{Stigma scale}

The stigma patients' perceptions of themselves and their illnesses were assessed using a 24-item, four-point Likert-type Stigma scale, with the internal consistency reaching 0.99 (Pan et al., 2007). Examples of the items include "I feel others avoid me because of my illness", "My job security has been affected by my illness", "I feel I need to keep my illness a secret" and "I feel set apart from others who are well". Responses to the items are scored from 1 (strongly disagree) to 4 (strongly agree), with a higher score indicating a higher perception of stigmatization. The internal consistency reliability (Cronbach's alpha) in this study was 0.93 .

\subsubsection{Mastery scale}

Mastery, or the extent to which individuals view their life circumstances as being under their personal control, was assessed using a seven-item, four-point Likert-type Mastery scale (Pearlin and Schooler, 1978). The reliability and validity of this instrument was confirmed in the prior studies (Pearlin et al., 1981; Rosenfield, 1992). Sample items include "I have little control over the things that happen to me", "What happens to me in the future mostly depends on me", and "There is little I can do to change many of the important things in my life". A mastery score is calculated by adding the scores of all items after reversing two negative items, with higher scores indicating a greater sense of mastery. The internal consistency reliability (Cronbach's alpha) in this study was 0.84 .

\subsubsection{Social support questionnaire}

Social support refers to an individual's level of satisfaction with the available support. This variable was assessed by a six-item Social Support Questionnaire (Short Form, SSQSF); responses were rated on a sixpoint Likert-type scale with the internal consistency ranging between 0.90 and 0.93 (Sarason et al., 1987). Social support scores are calculated by adding the scores of all items, with higher scores indicating greater satisfaction with the available support. The internal consistency reliability (Cronbach's alpha) in this study was 0.93 . 


\subsubsection{Quality of life scale}

QOL was assessed using the 28-item WHOQOLBREF (Taiwan version) (Yao et al., 2002). The WHOQOL-BREF is an abbreviated version of the 100item WHOQOL (Berlim et al., 2005). The reliability and validity of both instruments have been confirmed in numerous prior studies on patients suffering from major depression (Bonicatto et al., 2001; Skevington and Wright, 2001; Angermeyer et al., 2002; Trompenaars et al., 2005). The WHOQOL-BREF (Taiwan version) includes two general items (G1, covering overall QOL; and G4, covering general health), 24 universal items covering four domains (physical, psychological, social and environmental), and two items which are specific to Taiwanese culture (being respected/accepted by others, and eating the foods one loves).

Responses to the items are scored from 1 (least favorable condition) to 5 (most favorable condition). The domain scores, ranging from 4 to 20 , are calculated by taking the average scores for all items in the domain and then multiplying by 4 , with a higher score indicating a better QOL on the corresponding domain. The internal consistency reliabilities (Cronbach's alphas) in this study were found to be 0.84 for the physical domain, 0.87 for the psychological domain, 0.69 for the social domain, and 0.82 for the environmental domain.

\subsection{Data analysis}

Statistical analyses included descriptive statistics for each variable in the path model, computation of the correlation coefficients among all variables, and path analysis to validate the hypothetical model. We hypothesized that variations in QOL would depend on six predictive variables: age, gender, intensity of the depressive symptoms, perceived stigma, mastery and social support. QOL scores were those for the physical, psychological, social and environmental domains of the WHOQOL-BREF (Taiwan version). The significance level of the path analysis was set at 0.05 for the overall $F$-statistics, with individual $t$-statistics being obtained at each step, and for each path.

The first step in our analysis was the initial path model (the hypothesized model), followed by the second step, the final model, which was devised by deleting the insignificant paths from the initial model. These two steps were used to find better-fit models for each QOL domain for the patients. The goodness of fit between the data and the models was estimated by $P$-values for the Chi-squared test, root mean square error of approximation (RMSEA), goodness-of-fit index (GFI), adjusted goodness-of-fit index (AGFI), normed fit index (NFI)
Table 1

Sample demographic characteristics.

\begin{tabular}{|c|c|c|c|c|}
\hline Variables & Mean & S.D. & $n$ & $\%$ \\
\hline Age (years) & 46.95 & 13.70 & 237 & - \\
\hline Symptoms & 24.85 & 15.04 & 237 & - \\
\hline Support & 24.60 & 7.07 & 236 & - \\
\hline Mastery & 17.01 & 3.81 & 237 & - \\
\hline Stigma & 58.14 & 11.53 & 237 & - \\
\hline \multicolumn{5}{|l|}{ Quality of life } \\
\hline Physical domain & 11.71 & 2.90 & 237 & - \\
\hline Psychological domain & 10.53 & 3.31 & 237 & - \\
\hline Social domain & 11.46 & 2.64 & 237 & - \\
\hline Environmental domain & 12.86 & 2.48 & 237 & - \\
\hline \multicolumn{5}{|l|}{ Gender } \\
\hline Male & - & - & 61 & 25.7 \\
\hline Female & - & - & 176 & 74.3 \\
\hline \multicolumn{5}{|l|}{ Education } \\
\hline Uneducated & - & - & 8 & 3.4 \\
\hline Elementary & - & - & 40 & 16.9 \\
\hline High school & - & - & 113 & 47.6 \\
\hline College or above & - & - & 76 & 32.1 \\
\hline \multicolumn{5}{|l|}{ Employment status } \\
\hline Employed & - & - & 84 & 35.4 \\
\hline Unemployed & - & - & 153 & 64.6 \\
\hline \multicolumn{5}{|l|}{ Marital status } \\
\hline Single, never married & - & - & 46 & 19.4 \\
\hline Married & - & - & 148 & 62.4 \\
\hline Widowed, separated or divorced & - & - & 43 & 18.2 \\
\hline \multicolumn{5}{|l|}{ Living arrangements } \\
\hline Alone & - & - & 19 & 8.0 \\
\hline With family & - & - & 207 & 87.3 \\
\hline With friends & - & - & 11 & 4.6 \\
\hline
\end{tabular}

Note: Total sample number $=237$.

and comparative fit index (CFI) (Subhash, 1995). The criteria for a good fit were $P>0.05$, RMSEA $<0.05$, $\mathrm{GFI}>0.9, \mathrm{AGFI}>0.9, \mathrm{NFI}>0.9$ and $\mathrm{CFI}>0.9$. All of the analyses in this study were performed using SPSS (version 11.5) and LISREL 8.3.

\section{Results}

The majority of the 237 participants were female (74.3\%), had high school education or above $(79.7 \%)$ and had a mean age of 46.95 years (S.D. $=13.7$, range $=18-79$ years). About one-third of the participants $(35.4 \%)$ were employed, and most (87.3\%) lived with their families. The characteristics of the study participants are summarized in Table 1, whilst the correlation matrix for the variables used in the initial path model is presented in Table 2.

The results of the initial path model are as follows: Hypothesis 1 is not supported with the exception of (age to QOL) in the physical domain; Hypothesis 2 is supported for (gender to mastery) but not (gender to QOL); Hypothesis 3 is supported; Hypothesis 4 is 
Table 2

Correlation matrix for the variables in the path models.

\begin{tabular}{|c|c|c|c|c|c|c|}
\hline Variables & Age & Gender & Stigma & Mastery & Support & Symptoms \\
\hline Age & 1.000 & -0.019 & -0.243 & 0.233 & 0.102 & -0.287 \\
\hline Gender & -0.019 & 1.000 & -0.008 & -0.107 & 0.024 & 0.071 \\
\hline Stigma & -0.243 & -0.008 & 1.000 & -0.662 & -0.358 & 0.653 \\
\hline Mastery & 0.233 & -0.107 & -0.662 & 1.000 & 0.422 & -0.754 \\
\hline Support & 0.102 & 0.024 & -0.358 & 0.422 & 1.000 & -0.483 \\
\hline Symptoms & -0.287 & 0.071 & 0.653 & -0.754 & -0.483 & 1.000 \\
\hline \multicolumn{7}{|l|}{ QOL domains } \\
\hline Physical & 0.126 & -0.084 & -0.519 & 0.665 & 0.420 & -0.740 \\
\hline Psychological & 0.253 & -0.083 & -0.612 & 0.746 & 0.486 & -0.822 \\
\hline Social & 0.257 & -0.040 & -0.525 & 0.568 & 0.503 & -0.659 \\
\hline Environmental & 0.223 & -0.114 & -0.437 & 0.536 & 0.439 & -0.585 \\
\hline
\end{tabular}

supported with the exception of (stigma to QOL); Hypothesis 5 is supported by the data with the exception of (social support to QOL) in the physical domain; and Hypothesis 6 is supported with the exception of (mastery to QOL) in the social domain. In summary, three paths, (gender to QOL), (stigma to QOL), and (age to mastery), are not supported (Table 3). Additionally, (age to QOL) is not supported for the psychological, social and environmental domains. The respective paths of (social support to QOL) and (mastery to QOL) are not supported for the physical and social domains.

The values in the final path models for the four QOL domains (presented in Table 4 and Figs. 2-5) were: $P>0.05$, RMSEA $<0.05$, GFI $>0.9$, AGFI $>0.9$, $\mathrm{NFI}>0.9$, and $\mathrm{CFI}>0.9$, which suggests that these path models fit the data quite well. The results of the decomposition of the direct, indirect, causal and noncausal components of the final path model are presented in Table 5.

The physical QOL domain was directly predicted by age, mastery and intensity of the depressive symptoms (Fig. 2, Table 5), whilst the psychological and environmental QOL domains were directly predicted by mastery, social support and intensity of the depressive symptoms (Figs. 3 and 5), and the social QOL domain was directly predicted by social support and intensity of depressive symptoms (Fig. 4). Additionally, all four QOL domains were indirectly predicted by mastery and social support, and were only indirectly affected by gender and stigma.

In terms of the proportion of the variance explained in each QOL domain, the predictive variables explained $59.1 \%$ of the variance in the physical domain, $72.0 \%$ in the psychological domain, $47.9 \%$ in the social domain and $39.1 \%$ of the variance in the environmental domain. A combination of antecedent variables explained $49.6 \%$ of the variance in mastery, $12.9 \%$ in social support and $63.6 \%$ in depressive symptoms (Table 4 ).
We find that the intensity of the depressive symptoms had the greatest direct effect on all four QOL domains, with those patients with less severe depressive symptoms tending to have higher levels of QOL; that is,

Table 3

Path analysis for the initial model.

\begin{tabular}{|c|c|c|c|c|}
\hline $\begin{array}{l}\text { Dependent } \\
\text { variable }\end{array}$ & $\begin{array}{l}\text { Independent } \\
\text { variable }\end{array}$ & $\begin{array}{l}\text { Standardized } \\
\text { coefficient }\end{array}$ & $\begin{array}{l}\text { Regression } \\
\text { coefficient }\end{array}$ & $R^{2}$ \\
\hline \multirow[t]{4}{*}{ Mastery } & Age & 0.071 & 0.020 & \multirow[t]{4}{*}{0.496} \\
\hline & Gender & $-0.116^{*}$ & $-1.005^{*}$ & \\
\hline & Stigma & $-0.569^{*}$ & $-0.188^{*}$ & \\
\hline & Support & $0.214^{*}$ & $0.115^{*}$ & \\
\hline Support & Stigma & $-0.359^{*}$ & $-0.220^{*}$ & 0.129 \\
\hline \multirow[t]{3}{*}{ Symptoms } & Stigma & $0.249^{*}$ & $0.325^{*}$ & \multirow[t]{3}{*}{0.636} \\
\hline & Mastery & $-0.514^{*}$ & $-2.029 *$ & \\
\hline & Support & $-0.177^{*}$ & $-0.377^{*}$ & \\
\hline \multicolumn{5}{|l|}{ QOL domains } \\
\hline \multirow[t]{6}{*}{ Physical } & Age & $-0.096^{*}$ & $-0.020^{*}$ & \multirow[t]{6}{*}{0.591} \\
\hline & Gender & -0.022 & -0.147 & \\
\hline & Stigma & 0.003 & 0.001 & \\
\hline & Mastery & $0.241^{*}$ & $0.184^{*}$ & \\
\hline & Support & 0.060 & 0.025 & \\
\hline & Symptoms & $-0.554^{*}$ & $-0.107^{*}$ & \\
\hline \multirow[t]{6}{*}{ Psychological } & Age & 0.015 & 0.004 & \multirow[t]{6}{*}{0.721} \\
\hline & Gender & -0.019 & -0.143 & \\
\hline & Stigma & -0.048 & -0.014 & \\
\hline & Mastery & $0.259^{*}$ & $0.225^{*}$ & \\
\hline & Support & $0.096^{*}$ & $0.045^{*}$ & \\
\hline & Symptoms & $-0.545^{*}$ & $-0.120^{*}$ & \\
\hline \multirow[t]{6}{*}{ Social } & Age & 0.075 & 0.014 & \multirow[t]{6}{*}{0.496} \\
\hline & Gender & -0.009 & -0.051 & \\
\hline & Stigma & -0.116 & -0.026 & \\
\hline & Mastery & 0.086 & 0.059 & \\
\hline & Support & $0.233^{*}$ & $0.087^{*}$ & \\
\hline & Symptoms & $-0.386^{*}$ & $-0.068^{*}$ & \\
\hline \multirow[t]{6}{*}{ Environmental } & Age & 0.063 & 0.011 & \multirow[t]{6}{*}{0.398} \\
\hline & Gender & -0.077 & -0.433 & \\
\hline & Stigma & -0.033 & -0.007 & \\
\hline & Mastery & $0.171^{*}$ & $0.111 *$ & \\
\hline & Support & $0.200^{*}$ & $0.070^{*}$ & \\
\hline & Symptoms & $-0.316^{*}$ & $-0.052 *$ & \\
\hline
\end{tabular}

Note: * indicates $P<0.05$. 
Table 4

Path analysis for the final model.

\begin{tabular}{llrrr}
\hline $\begin{array}{l}\text { Dependent } \\
\text { variable }\end{array}$ & $\begin{array}{l}\text { Independent } \\
\text { variable }\end{array}$ & $\begin{array}{l}\text { Standardized } \\
\text { coefficient }\end{array}$ & $\begin{array}{l}\text { Regression } \\
\text { coefficient }\end{array}$ & $R^{2}$ \\
\hline Mastery & Gender & $-0.117^{*}$ & $-1.018^{*}$ & 0.492 \\
& Stigma & $-0.585^{*}$ & $-0.194^{*}$ & \\
& Support & $0.215^{*}$ & $0.116^{*}$ & \\
Support & Stigma & $-0.359^{*}$ & $-0.220^{*}$ & 0.129 \\
Symptoms & Stigma & $0.249^{*}$ & $0.325^{*}$ & 0.636 \\
& Mastery & $-0.514^{*}$ & $-2.029^{*}$ & \\
QOL domains & Support & $-0.177^{*}$ & $-0.377^{*}$ & \\
Physical & Age & $-0.098^{*}$ & $-0.021^{*}$ & 0.591 \\
& Mastery & $0.250^{*}$ & $0.192^{*}$ & \\
& Symptoms & $-0.574^{*}$ & $-0.112^{*}$ & \\
Psychological & Mastery & $0.280^{*}$ & $0.244^{*}$ & 0.720 \\
& Support & $0.095^{*}$ & $0.044^{*}$ & \\
& Symptoms & $-0.565^{*}$ & $-0.124^{*}$ & \\
Social & Support & $0.241^{*}$ & $0.090^{*}$ & 0.479 \\
& Symptoms & $-0.542^{*}$ & $-0.095^{*}$ & \\
Environmental & Mastery & $0.196^{*}$ & $0.128^{*}$ & 0.391 \\
& Support & $0.190^{*}$ & $0.067^{*}$ & \\
& Symptoms & $-0.345^{*}$ & $-0.057^{*}$ & \\
\hline
\end{tabular}

Note: * indicates $P<0.05$.

patients' symptom distress levels were negatively associated with their QOL. Stigma had the greatest indirect effect on all four domains, with this effect being mediated through the intensity of the depressive symptoms, mastery and social support. Patients who perceived higher stigmatization had poorer QOL through the aforementioned mediators.

Finally, mastery and social support had the second and third largest indirect effects on all domains, despite the differences between these two indirect effects being insignificant. Amongst the six predictive variables, the

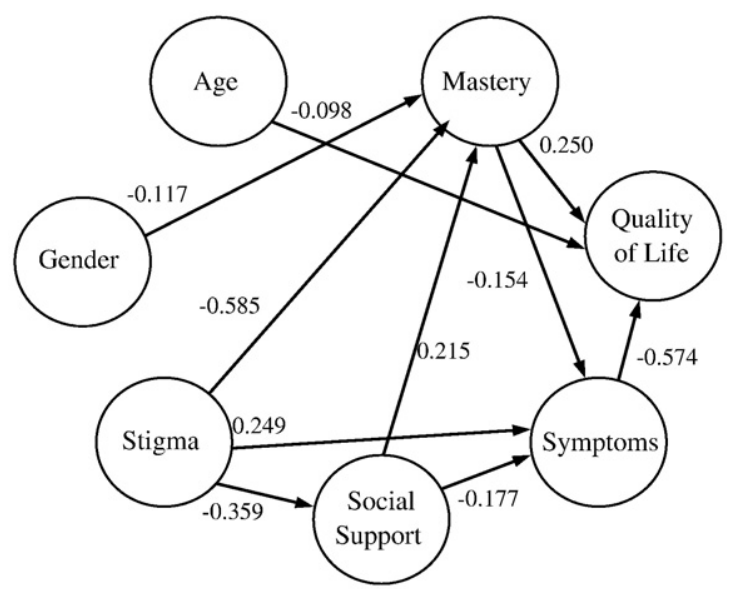

Fig. 2. Final path model for the physical quality of life domain.

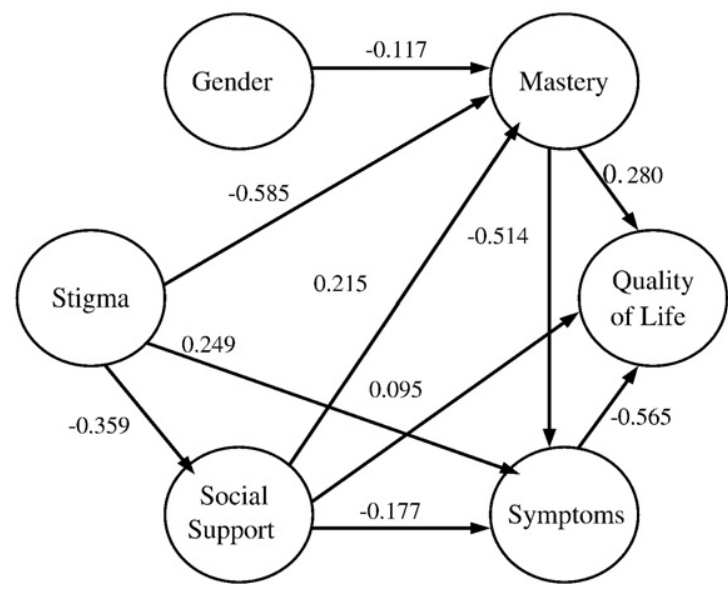

Fig. 3. Final path model for the psychological quality of life domain.

largest direct and indirect effects were (stigma to mastery) and (stigma to intensity of depressive symptoms), respectively. Mastery had the second largest direct effect on intensity of the depressive symptoms.

\section{Discussion and conclusions}

Our results show that a key determinant for all QOL domains was the intensity of the depressive symptoms. The secondary determinants for patients' QOL were social support and stigma, with social support having not only a direct effect on QOL, but also an indirect effect, mediated through the intensity of the depressive symptoms. Although stigma did not directly affect QOL, it did have an indirect effect mediated through the intensity of the depressive symptoms, mastery and social support. Furthermore, higher levels of mastery

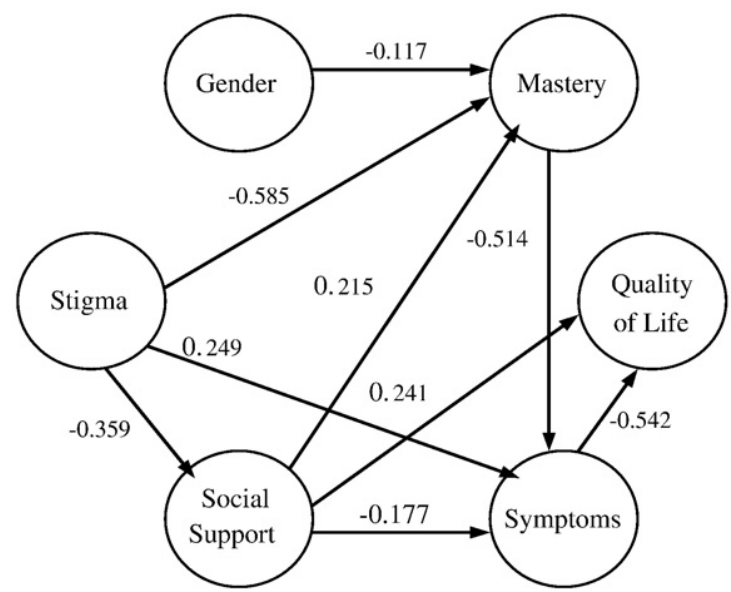

Fig. 4. Final path model for the social quality of life domain. 


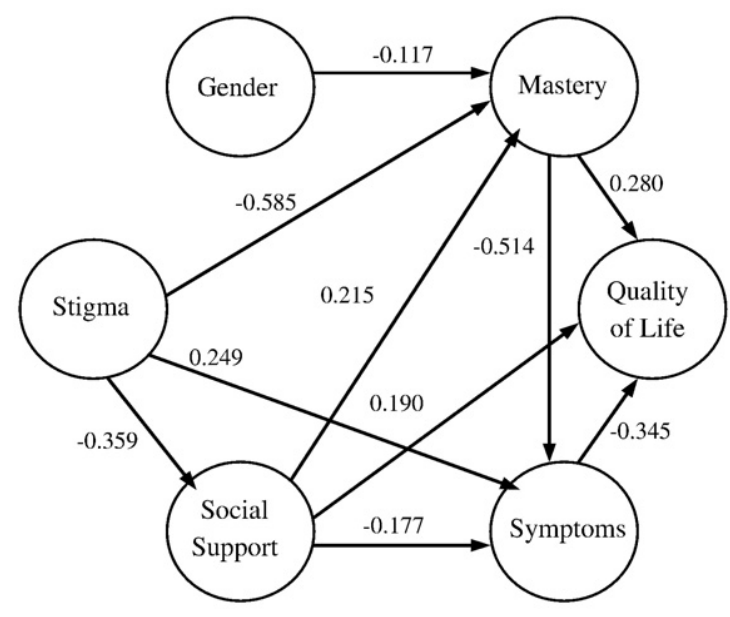

Fig. 5. Final path model for the environmental quality of life domain.

were both directly and indirectly associated with higher QOL levels, as a result of fewer depressive symptoms.

\subsection{Intensity of depressive symptoms}

This study finds that the intensity of the depressive symptoms has the greatest direct effect on all four QOL domains; in other words, in all aspects of the patients' lives, high levels of depression are associated with poorer quality of life. The patients in this study were least satisfied with negative feelings, life enjoyment, meaning in their lives, and sufficient sleep. These perceptions reflected depressive symptoms, such as depressed mood, loneliness, restlessness and lack of motivation. Clearly, depressed mood may lead to extreme forms of behavior, such as suicide (Chan et al., 2006).

Depressive symptoms and the social functioning of individuals suffering from depression have, for several decades, been successfully treated with antidepressants (Stewart et al., 1988; Markowitz et al., 1996) and psychotherapy (Weissman et al., 1974, 1981; Hirschfeld et al., 2002). Nevertheless, some of the more recent clinical trials demonstrate that antidepressants can effectively improve patients' depressive symptoms and QOL (Aberg-Wistedt et al., 2000; Carpenter et al., 2002). Practitioners should therefore continue to develop treatment programs aimed at improving depressive symptoms, thereby potentially increasing the QOL of patients with major depression.

\subsection{Stigma}

We find that stigma has direct effects on the intensity of patients' depressive symptoms, social support and mastery for all four QOL domains, findings which are consistent with those of the prior studies (Perlick, 2001; Perlick et al., 2001; Pyne et al., 2004). Additionally, stigma has the greatest indirect effect on patients' QOL; those patients with a higher sense of stigmatization had poorer QOL as mediated through the intensity of the depressive symptoms, mastery and social support.

Within Chinese society, the degree of stigmatization is high for patients suffering from mental illnesses; indeed, being respected by others, or 'saving face', is particularly important in Chinese culture (Chung et al., 2003). Patients with chronic diseases, such as asthma, diabetes or cardiovascular disease, are not stigmatized since the causes of these diseases are publicly known; however, patients with mental illnesses can be seriously stigmatized since the causes of these illnesses are unknown. Chinese people tend to believe that mental illness can result from a lack of cleanliness, bad heritage or supernatural powers (e.g., evil spirits), so Chinese patients with mental illness are afraid that if their illness is discovered, they will be disrespected by others.

Patients with depression tend to prefer alternative medicine (e.g., Chinese medicine and conjuration) due to their personal and family concerns over the causes of these diseases and cultural factors (Pan, 2005); thus, patients suffering from mental illnesses may hesitate to

Table 5

Decomposition of the final path model for the four QOL domains.

\begin{tabular}{lllrr}
\hline $\begin{array}{l}\text { QOL domain bivariate } \\
\text { relationships }\end{array}$ & Direct & Indirect & $\begin{array}{l}\text { Non- } \\
\text { causal }\end{array}$ & Total \\
\hline Physical & & & & \\
(Age, QOL) & -0.098 & - & 0.224 & 0.126 \\
(Gender, QOL) & - & -0.064 & -0.020 & -0.084 \\
(Stigma, QOL) & - & -0.540 & 0.021 & -0.519 \\
(Mastery, QOL) & 0.250 & 0.295 & 0.120 & 0.665 \\
(Support, QOL) & - & 0.219 & 0.201 & 0.420 \\
(Symptoms, QOL) & -0.574 & - & -0.166 & -0.740 \\
Psychological & & & & \\
(Gender, QOL) & - & -0.067 & -0.016 & -0.083 \\
(Stigma, QOL) & - & -0.589 & -0.023 & -0.612 \\
(Mastery, QOL) & 0.281 & 0.290 & 0.175 & 0.746 \\
(Support, QOL) & 0.095 & 0.223 & 0.168 & 0.486 \\
(Symptoms, QOL) & -0.565 & - & -0.257 & -0.822 \\
Social & & & & \\
(Gender, QOL) & - & -0.033 & -0.007 & -0.040 \\
(Stigma, QOL) & - & -0.441 & -0.084 & -0.525 \\
(Mastery, QOL) & - & 0.279 & 0.289 & 0.568 \\
(Support, QOL) & 0.241 & 0.156 & 0.106 & 0.503 \\
(Symptoms, QOL) & -0.542 & - & -0.111 & -0.653 \\
Environmental & & & & \\
(Gender, QOL) & - & -0.044 & -0.070 & -0.114 \\
(Stigma, QOL) & - & -0.423 & -0.014 & -0.437 \\
(Mastery, QOL) & 0.196 & 0.177 & 0.163 & 0.536 \\
(Support, QOL) & 0.191 & 0.141 & 0.107 & 0.439 \\
(Symptoms, QOL) & -0.345 & - & -0.240 & -0.585 \\
\hline & & & &
\end{tabular}


seek medical support or help from relatives or neighbors. Such hesitation usually delays treatment, so that when Chinese patients do eventually seek medical support, their symptoms may be quite severe. Thus, perceived stigma adversely affects not only social functioning and QOL, but also self-esteem and adherence to antidepressant medication (Link et al., 2001; Sirey et al., 2001).

In order to reduce stigma and its adverse effects, multidimensional programs are needed to mobilize society at both the individual and community levels (Warner, 2005). For example, treatment programs aimed at improving a person's ability to cope with perceived stigma could be considered. In addition to personal level interventions, community programs could include raising the awareness of the general public with regard to depressive symptoms, as well as the promotion of depression screening.

\subsection{Social support}

Our results indicate that social support has a positive association with QOL, particularly the social QOL domain - since patients with greater social support provided a higher personal QOL rating - whilst social support also indirectly affects QOL through the intensity of the depressive symptoms; these findings are consistent with those of a prior related study (Trompenaars et al., 2005).

In Chinese culture, parents are expected to take good care of their children even after they are grown and/or married; conversely, children are regarded as the main source of support for their parents, and are expected to look after them in later life. However, due to recent large-scale changes in socio-economic development, Chinese family support systems are less well maintained than in the past, with family members having less contact and greater independence; and indeed, it may be difficult for Chinese people to cope with these changes (Yip et al., 2002; Chan et al., 2006). If the healthcare system in Taiwan, which is funded by general taxation, could provide greater support for social and mental healthcare, the quality of life of Chinese patients suffering from depression may be improved.

\subsection{Gender and mastery}

About three-quarters of the patients in our study sample were women, consistent with the epidemiological results indicating that more women suffer from depression than men (World Health Organization, 2004). Men tend to suppress their feelings and may perceive the need for assistance for emotional problems as a sign of weakness (Thompson, 2000), making it difficult to detect depression in men. This viewpoint holds for Chinese culture, where men are expected to be strong, masculine figures, hiding their feelings or powerlessness (Yip, 2003; Chan et al., 2006). Our results also show that men with depression tend to have a stronger sense of mastery than women with depression. This finding is consistent with a previous study reporting a stronger sense of mastery in Asian males than females, a tendency attributed to the role of men as the main economic resource and head of the household (Chung et al., 2003). This study confirms that gender has an indirect effect on QOL, mediated through mastery.

Low levels of perceived mastery compromise quality of life by producing a sense of hopelessness and a tendency to give up in difficult times, thus diminishing chances for life satisfaction. The relationship between perceived mastery and QOL is already well documented (Pearlin et al., 1981; Rosenfield, 1992). Our results indicate that higher levels of mastery are both directly and indirectly associated with higher levels of QOL, with the indirect effect resulting from fewer depressive symptoms.

Perceptions of mastery account for the impact of interventions aimed at increasing economic resources and raising empowerment status on life satisfaction (Rosenfield, 1992). Diminished mastery leaves a person vulnerable to symptoms of depression (Pearlin et al., 1981); thus, intervention programs which provide actual or perceived control have considerable potential for maximizing patients' mental health, preventing subsequent distress, and successfully raising their QOL.

Some limitations of this study are: (i) the sample composed mainly of females; (ii) patients were recruited, by convenience, from a single hospital in northern Taiwan; and (iii) we have no information on either the duration of the patients' current depressive episode or the number of prior episodes. Thus, any attempts to generalize these results to other populations of patients with depression should be undertaken with caution.

In conclusion, comprehensive programs need to be developed to educate the public about mental illness and the importance of seeking medical services at the earliest possible stage of the illness. High-quality treatment programs emphasizing a reduction in depressive symptoms and enhancing patients' social support and mastery, combined with interventions for reducing stigma, could more effectively improve all aspects of QOL for patients with depression. Future research could evaluate the benefits of domain-specific treatment modalities on patients' QOL, with cost-effective analyses also potentially contributing to the allocation of treatment aimed at eliciting the best QOL outcomes. 


\section{Acknowledgements}

This study was supported by grants from the Department of Health (DOH93-TD-M-113-031) and the National Science Council (NSC93-2314-B-002-294, NSC94-2314-B-002-223) within the Executive Yuan of Taiwan, for which we are extremely grateful.

\section{References}

Aberg-Wistedt, A., Agren, H., Ekselius, L., Bengtson, F., Akerblad, A.C.M., 2000. Sertraline versus paroxetine in major depression: clinical outcome after six months of continuous therapy. Journal of Clinical Psychopharmacology 20 (6), 645-652.

Angermeyer, M.C., Holzinger, A., Matschinger, H., Strengler-Wenzke, K., 2002. Depression and quality of life: results of a follow-up study. International Journal of Social Psychiatry 48 (3), 189-199.

Bachrach, L.L., 1987. The chronic psychiatric patient as a difficult patient. In: Meyerson, A.T. (Ed.), Barriers to treating the chronic mentally ill. Jossey-Bass, San Francisco, pp. 35-50.

Ben-Zur, H., 2002. Coping, affect and aging: the roles of mastery and self-esteem. Personality and Individual Differences 32, 357-372.

Berlim, M.T., Pavanello, D.P., Caldieraro, M.A.K., Fleck, M.P.A., 2005. Reliability and validity of the WHOQOL BREF in a sample of Brazilian outpatients with major depression. Quality of Life Research 14, $561-564$

Bonicatto, S.C., Dew, M.A., Zaratiegui, R., Lorenzo, L., Pecina, P., 2001. Adult outpatients with depression: worse quality of life than in other chronic medical disease in Argentina. Social Science and Medicine 52, 911-919.

Carpenter, L.L., Yasmin, S., Price, L.H., 2002. A double -blind, placebo-controlled study of antidepressant augmentation with mirtazapine. Biological Psychiatry 51 (2), 183-188.

Carpiniello, B., Lai, G.L., Pariante, C.M., Carta, M.G., Rudas, N., 1997. Symptoms, standards of living and subjective quality of life: a comparative study of schizophrenic and depressed out-patients. Acta Psychiatrica Scandinavica 96 (4), 235-241.

Chan, S.W.C., Chiu, H.F.K., Chien, W., Thompson, D.R., Lam, L., 2006. Quality of life in Chinese elderly people with depression. International Journal of Geriatric Psychiatry 21, 312-318.

Chien, C.P., Cheng, T.A., 1985. Depression in Taiwan: epidemiological survey utilizing CES-D. Psychiatria et Neurologia Japonica 87 (5), 335-338.

Chung, L., Pan, A.W., Wang, Y.H., 2003. A causal model of rehabilitation resource use for subject with spinal cord injury in Taiwan. Journal of Rehabilitation Medicine 35 (5), 208-212.

Corrigan, P., Thompson, V., Lambert, D., Sangster, Y., Noel, J.G., Campbell, J., 2003. Perceptions of discrimination among persons with serious mental illness. Psychiatric Services 54 (8), $1105-1110$.

Heckman, T.G., 2003. The chronic illness quality of life (CIQOL) model: explaining life satisfaction in people living with HIV disease. Health Psychology 22 (2), 140-147.

Hirschfeld, R.M.A., Dunner, D.L., Keitner, G., Klein, D.N., Koran, L.M., Kornstein, S.G., Markowitz, J.C., Miller, I., Nemeroff, C.B., Ninan, P.T., Rush, A.J., Schatzberg, A.F., Thase, M.E., Trivedi, M.H., Borian, F.E., Crits-Christoph, P., Keller, M.B., 2002. Does psychosocial functioning improve independent of depressive symptoms: a comparison of nefazodone, psychotherapy, and their combination. Biological Psychiatry 51 (2), 123-133.
Lamb, H.R., 1976. Community survival for long-term patients. JosseyBass, San Francisco.

Lamb, H.R., 1982. Young adult chronic patients: the new drifters. Hospital and Community Psychiatry 33, 465-468.

Link, B.G., Cullen, F.T., Frank, J., Wozniak, J.F., 1987. The social rejection of former mental patients: understanding why labels matter. American Journal of Sociology 92, 1461-1500.

Link, B.G., Phelan, J.C., Bresnahan, M., Stueve, A., Pescosolido, B.A., 1999. Public conceptions of mental illness: labels, causes, dangerousness, and social distance. American Journal of Public Health 89 (9), $1328-1333$.

Link, B.G., Struening, E.L., Neese-Todd, S., Asmussen, S., Phelan, J.C., 2001. The consequence of stigma for the self-esteem of people with mental illness. Psychiatric Services 52 (12), 1621-1626.

Markowitz, R.E., 1998. The effects of stigma on the psychological well-being and life satisfaction of persons with mental illness. Journal of Health and Social Behavior 39, 335-347.

Markowitz, J.C., Friedman, R.A., Miller, N., Spielman, L.A., Moran, M.E., Kocsis, J.H., 1996. Interpersonal improvement in chronically depressed patients treated with desipramine. Journal of Affective Disorders 41 (1), $59-62$.

Merton, R., 1946. Mass Persuasion. Harpers, New York.

Michalak, E.E., Tam, E.M., Manjunath, C.V., Solomons, K., Levitt, A.J., Levitan, R., Enns, M., Morehouse, R., Yatham, L.N., Lam, R.W., 2004. Generic and health-related quality of life in patients with seasonal and nonseasonal depression. Psychiatry Research 128 (3), 245-251.

Munoz, R.A., McBride, M.E., Brnabic, A.J., Lopez, C.J., Hetem, L.A., Secin, R., Duenas, H.J., 2005. Major depressive disorder in Latin America: the relationship between depression severity, painful somatic symptoms, and quality of life. Journal of Affective Disorders 86 (1), 93-98.

Pan, J.J., 2005. The use of alternative medicine among Taiwanese psychiatric outpatients. Psychiatry and Clinical Neurosciences 59, 711-716.

Pan, A.W., Chan, P.S., Chung, L., Chen, T.J., Hsiung, P.C., 2006. Quality of life in depression: predictive models. Quality of Life Research 15, 39-48.

Pan, A.W., Chung, L., Fife, B.L., Hsiung, P.C., 2007. Evaluation of the psychometrics of the Social Impact Scale: a measure of stigmatization. International Journal of Rehabilitation Research 30 (3), 235-238.

Pearlin, L.I., Schooler, C., 1978. The structure of coping. Journal of Health and Social Behavior 19 (1), 2-21.

Pearlin, L.I., Menaghan, E.G., Lieberman, M.A., Mullan, J.T., 1981. The stress process. Journal of Health and Social Behavior 22 (4), 337-356.

Pedhazur, E.J., 1982. Multiple regression and behavioral science. Harcourt Brace, Orlando, FL.

Perlick, D.A., 2001. Special section on stigma as a barrier to recovery: introduction. Psychiatric Services 52 (12), 1613-1614.

Perlick, D.A., Rosenheck, R.A., Clarkin, J.F., Sirey, J.A., Salahi, J., Struening, E.L., Link, B.G., 2001. Adverse effects of perceived stigma on social adaptation of persons diagnosed with bipolar affective disorder. Psychiatric Services 52 (12), 1627-1632.

Pyne, J.M., Kuc, E.J., Schroeder, P.J., Fortney, J.C., Edlund, M., Sullivan, G., 2004. Relationship between perceived stigma and depression severity. The Journal of Nervous and Mental Disease 192 (4), 278-283.

Rosenfield, S., 1986. The effects of women's employment: personal control and sex differences in mental health. Journal of Health and Social Behavior 30, 77-91. 
Rosenfield, S., 1992. Factors contributing to the subjective quality of life of the chronic mentally ill. Journal of Health and Social Behavior 33 (4), 299-315.

Rosenfield, S., 1997. Labeling mental illness: the effect of received services and perceived stigma on life satisfaction. American Sociological Review 62 (4), 660-672.

Rotter, J.B., 1966. Generalized expectancies for internal vs. external control of reinforcement. Psychological Monographs 80, 1-28.

Rüesch, P., Graf, J., Meyer, P.C., Rössler, W., Hell, D., 2004. Occupation, social support and quality of life in persons with schizophrenic or affective disorders. Social Psychiatry and Psychiatric Epidemiology 39, 686-694.

Sarason, I.G., Sarason, B.R., Shearin, E.N., Pierce, G.R., 1987. A brief measure of social support: Practical and theoretical implications. Journal of Social and Personal Relationships 4 (4), 497-510.

Sirey, J.A., Bruce, M.L., Alexopoulos, G.S., Perlick, D.A., Friedman, S.J., Meyers, B.S., 2001. Perceived stigma and patient-rated severity of illness as predictors of antidepressant drug adherence. Psychiatric Services 52 (12), 1615-1620.

Skevington, S.M., Wright, A., 2001. Changes in the quality of life of patients receiving antidepressant medication in primary care: validation of the WHOQOL-100. British Journal of Psychiatry 178, 261-267.

Stewart, J.W., Quitkin, F.M., McGrath, P.J., Rabkin, J.G., Markowitz, J.S., Tricamo, E., Klein, D.F., 1988. Social functioning in chronic depression: effect of 6 weeks of antidepressant treatment. Psychiatry Research 25 (2), 213-222.

Subhash, S., 1995. Applied multivariate techniques. Springer, New York. Thompson, D., 2000. The male role stereotype (3rd.). Mayfield, California. Trompenaars, F.J., Masthoff, E.D., Heck, G.L.V., Hodiamont, P.P., Vries, J.D., 2005. Content validity, construct validity, and reliability of the WHOQOL-Bref in a population of Dutch adult psychiatric outpatients. Quality of Life Research 14, 151-160.

Veblen, T., 1899. The theory of the leisure class. Macmillan, New York.

Warner, R., 2005. Local project of the world psychiatric association programme to reduce stigma and discrimination. Psychiatric Services 56 (5), 570-575.

Weissman, M.M., Klerman, G.L., Paykel, E.S., Prusoff, B., Hanson, B., 1974. Treatment effects on the social adjustment of depressed patients. Archives of General Psychiatry 30 (6), 771-778.

Weissman, M.M., Klerman, G.L., Prusoff, B.A., Sholomskas, D., Padian, N., 1981. Depressed outpatients. Results one year after treatment with drugs and/or interpersonal psychotherapy. Archives of General Psychiatry 38 (1), 51-55.

World Health Organization, 2004. World Health Report. Geneva, WHO.

Wills, T.A., 1998. Social support. Guilford Press, New York.

Wright, E.R., Gronfein, W.P., Owens, T.J., 2000. Deinstitutionalization, social rejection, and the self-esteem of former mental patients. Journal of Health and Social Behavior 41, 68-90.

Yao, G., Chung, C.W., Yu, C.F., Wang, J.D., 2002. Development and verification of validity and reliability of the WHOQOL-BREF Taiwan version. Journal of Formosa Medical Association 101 (5), 342-351.

Yip, K.S., 2003. Gender differences in mental illness in Hong Kong. Administration Policy Mental Health 30, 361-368.

Yip, P., Chi, I., Chiu, H., 2002. A multi-disciplinary study on the cause of elderly suicide in Hong Kong. Elderly Commission, The Government of Hong Kong Special Administrative Region, Hong Kong.

Yu, C.T., 2004. Quality of life and its related factors of outpatients with Major Depression Disorder. National Taiwan University Graduate Institute of Nursing Master Thesis. 